\title{
Interfacial Temperature Discontinuities in a Thin Liquid Layer during Evaporation
}

\author{
Zhi-Qiang Zhu • Qiu-Sheng Liu
}

Received: 14 December 2012 / Accepted: 5 September 2013 / Published online: 28 September 2013

(C) Springer Science+Business Media Dordrecht 2013

\begin{abstract}
Recent measurements of the temperature profiles across the liquid-vapor interface of a steady evaporating liquid were performed in a thin planar liquid layer subjected to externally imposed horizontal temperature differences when the interface was open to air. Temperature discontinuities have been found to exist at the interface with an growing tendency as the imposed horizontal temperature difference increasing. Under the co-influence of thermocapillary convection and evaporation effect, a thin layer of $0.5 \mathrm{~mm}$ thick with approximate uniform temperature was found just below the liquid-vapor interface. Repeated experiments and further comparisons of the interfacial temperature profiles for different spatial positions along the streamwise center line and varying depths of the liquid layer were also carried out. And the temperature discontinuity was found related to the temperature in liquid phase, which was strongly influenced by the coupling of thermocapillary convection and evaporation effect.
\end{abstract}

Keywords Thermocapillary convection - Evaporation . Temperature discontinuity

\section{Introduction}

Evaporation or condensation process has given rise to increasing interests owing to not only its wild existence in

Z.-Q. Zhu · Q.-S. Liu ( $₫)$

Key Laboratory of Microgravity (National Microgravity

Laboratory), Institute of Mechanics, Chinese Academy

of Sciences, Beijing 100190, China

e-mail: liu@imech.ac.cn

Z.-Q. Zhu

e-mail: zhuzhiqiang@imech.ac.cn nature but also its great applications in industry engineering, such as thin-film evaporators, heat pipes and boiling equipments. Many experimental and theoretical studies have been performed to understand the physical mechanisms for liquids evaporating across the liquid-vapor interface freely. Since the classical kinetic theory of gases (KTG) provided the molecular basis for understanding the evaporation process over one century ago (Hertz 1882; Stefan 1891; Knudsen 1915), the thermal equilibrium (continuity of temperature) was usually assumed across the liquidvapor interface. However, a temperature discontinuity at the liquid-vapor interface has been reported by several researchers. Ward and co-workers (Fang and Ward 1999a; Ward and Stanga 2001; McGaughey and Ward 2002; Ward and Duan 2004) carried out a series of experiments in a vacuum chamber with pure water, significant temperature discontinuities up to $7.8^{\circ} \mathrm{C}$ were found at the liquid-vapor interface and the vapor temperatures close to the interface were always higher than those in the liquid phase under the steady-evaporation condition. It is interesting that the temperature discontinuity was strongly depended on the vapor pressure, with increasing temperature discontinuity as the vapor pressure decreasing. Compared between Ward's results and the predictions by classical kinetic theory, a great conflict was found for the evaporating rate at the interface. Therefore, Ward and Fang (1999) and Fang and Ward (1999b) proposed statistical rate theory (SRT) to predict the liquid evaporating rate based on the measured temperature discontinuity at the interface. And the SRT approach was found accurately to predict the experimental conditions. It is reasonable to suppose that the KTG with the assumption of thermal-equilibrium at the liquid-vapor interface could not effective in an evaporating liquid-vapor system. 
During evaporation, an essential mechanism is that evaporation leads to intensive cooling of the liquid-vapor interface. In previous literatures, evaporation has been found to influence the interfacial temperature profile and the convective instability significantly (Yamamura et al. 2003). Recently, motivated by the great requirements in space engineering, people began to take evaporation into account when studying the instability of surface-tension-driven convection. Thermocapillary convection is one of the most mentioned convection, which is driven by the surface tension gradient induced by temperature variations along the free interface. Actually, many experimental and numerical works have been done to identify and enrich understanding of the instability mechanisms of thermocapillary convection since Smith and Davis (1983a, b) performed linear stability analysis of a liquid layer subjected to a horizontal temperature gradient. Undoubtedly, the cognizance for the pure thermocapillary convection has been basically clear.

According to previous researches on the convective instability with an evaporating liquid-vapor interface, evaporation and thermocapillary convection were found to always couple with each other and co-influence the interfacial characteristics, such as interfacial temperature and pressure (Ji and Liu 2008; Zhu and Liu 2010). Actually, besides the temperature discontinuity across the liquid-vapor evaporating interface, Ward and co-workers (Duan and Ward 2005a, b; Duan et al. 2005) also found the existence of the thermocapillary convection in the steady-evaporating water. After careful measurements, the results indicated that thermal conduction to the interface could not provide enough energy for the evaporation at the liquid-vapor interface, and perhaps thermocapillary convection transport and provide the remaining heat energy. Of all the required heat to evaporate the liquid at the observed rate, thermocapillary convection could account for as much as $50 \%$ in maxima. Also, an uniform-temperature layer with a thickness of about $0.5 \mathrm{~mm}$ just below the interface was observed and it is reasonable to suppose that this may be resulted from the coupling influence of thermocapillary convection and evaporation.

In above-mentioned literatures, people either treated the liquid-vapor interface under thermal equilibrium based on classical kinetic theory of gases (KTG), or observed the temperature discontinuity only by use of water at $4{ }^{\circ} \mathrm{C}$ in extreme vacuum conditions as low as serval hundred pascals. It is not certain if the temperature discontinuity could be universal to extend to general-existing air conditions, such as around room temperature and standard atmospheric pressure.

Anyhow,the coupling influence of evaporation effect and thermocapillary convection on the heat transfer at the liquidvapor interface is complex and need to be understood. In this paper, we focus on the non-equilibrium effect of evaporation. And experimental results will be presented on the vertical temperature profiles across the liquid-vapor interface concerning the co-influence of evaporation effect and thermocapillary convection in a thin free evaporating liquid layer with the interface open to air.

In the following, "Experimental Setup and Measurement Techniques" first describes details of the apparatus for measurements. In "Results and Discussion", the experimental results obtained from a quasi-evaporating liquid layer will be presented, including the temperature discontinuity at the liquid-vapor interface for different horizontal temperature differences, streamwise positions and depths of the liquid layer. Finally, major conclusions and preliminary discussion of the work are summarized in "Conclusion".

\section{Experimental Setup and Measurement Techniques}

The experiments were carried out in a rectangular test cell, with a length and width of $80 \mathrm{~mm}$ and $40 \mathrm{~mm}$, respectively, as shown in Fig. 1 of the overall schematic diagram of the experimental apparatus. As we know, as soon as a horizontal temperature gradient achieves parallel to the liquid-vapor interface, there will be immediate thermocapillary convection along the interface, which is induced by the distributed liquid surface tension at the free interface. The test cell we used were constructed of two aluminum blocks at opposite sides for thermal control and two pieces of optical glass perpendicular to the two aluminum sidewalls for experimental observations. Actually, the thermal conductivity of aluminum is two orders of magnitude better than that of optical glass, which could minimize the thermal disturbance conducted from the glass sidewall. On account of the same consideration, the bottom wall of the test cell was also made of optical glass to play the role of thermal insulation. Before each experiment, the test cell was leveled with good precision over $\mathrm{x}$ - and $\mathrm{y}$-directions. In present paper, we studied the evaporating liquid layer with free liquid-vapor interface, i.e. the liquid layer evaporated freely with the test cell open to air. During the whole experimental process, the room temperature, which was controlled by an air conditioner to be stable at $20^{\circ} \mathrm{C}$, atmosphere pressure and humidity were measured using a weather station. The present evaporating experiments were carried out under atmosphere temperature of $20{ }^{\circ} \mathrm{C}$, pressure of $1 \mathrm{~atm}$ and humidity of $40-50 \%$. In addition, the whole apparatus was placed in a plexiglas box to minimize disturbance of the environmental air flow.

The thermocapillary convection was induced by means of the horizontal temperature difference $(\Delta T)$ control of the two aluminum sidewalls of the test cell. Cool water with constant temperature flowing out of a refrigerated circulator was circulated into the left sidewall, and the accuracy of the temperature could be $0.02{ }^{\circ} \mathrm{C}$. Meanwhile, an electrical heater was attached to the another aluminum sidewall, 


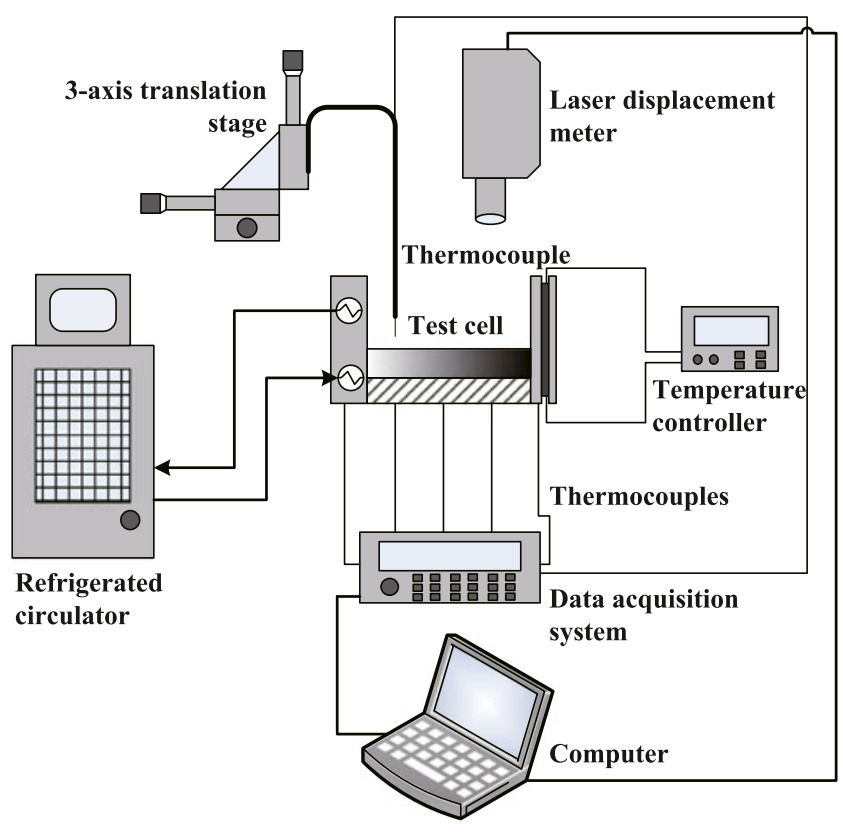

Fig. 1 Schematic drawing of the experimental apparatus

of which the temperature was controlled by PID loops with an accuracy of $0.05{ }^{\circ} \mathrm{C}$. In present experiments, four thermocouples were insert into the aluminum sidewalls to monitor the temperature variation, and the results verified the imposed temperatures' uniformity and stability.

In order to measure the interfacial temperature profiles accurately, a type $\mathrm{T}$ thermocouple with a diameter of $50 \mu \mathrm{m}$ was chosen due to its advantages of good spatial resolution, rapid response time $(0.02 \mathrm{~s})$ and small size to avoid disturbance to the liquid layer inner flow. The thermocouple could be moved at different directions with the help of a 3-axis electric translation stage with an accuracy of $\pm 1 \mu \mathrm{m}$. The temperatures were acquired by a data acquisition system. A computer programmed and controlled the translation stage and the data acquisition system to obtain the temperature data at different spatial and temporal intervals. Before using the thermocouple, we verified and calibrated the thermocouple by measuring typical temperature of boiling point of several liquids, such as ethanol, water, FC-72 and acetone.

In present experiments, temperature was measured by moving down the $50 \mu \mathrm{m}$ thermocouple vertically from vapor to liquid phase. The thermocouple was first positioned $1.0 \mathrm{~mm}$ above the liquid-vapor interface to begin measuring the vapor temperature. Near the interface, the interval between two measurement in the vertical direction was $50 \mu \mathrm{m}$ in the vapor and liquid phase. Additionally, it took about $15 \mathrm{~s}$ for recording each measurement and calculating the average temperature with the hypothesis of steady-state. Comparing with the much smaller response time $(0.02 \mathrm{~s})$ of the thermocouple, this measuring interval could ensure the accuracy.

A silicone oil with kinematic viscosity of $0.65 \mathrm{cSt}$, Plandtl number of 10 was put into the test cell before each experiment, of which the thermo-physical properties at $25^{\circ} \mathrm{C}$ and $1 \mathrm{~atm}$ were presented in Table 1 . It was chosen not only for its desirable constant physical characteristic, resistance to surface contamination and extensive use in industry, but also for its relatively high saturated vapor pressure under atmosphere condition.

Decrease of the liquid layer thickness induced by evaporation effect was monitored at the center of the layer in use of a laser co-focal displacement meter with an accuracy of $0.3 \mu \mathrm{m}$. The measurement indicated that the layer thickness decreased approximately linearly with time (Zhu and Liu 2010), which partly supported the hypothesis of quasi-stable evaporating condition in present experiments. Under the above quasi-stable condition, we performed the measurements as soon as possible, and the liquid layer thickness in one experiment was assumed to be approximately constant with the evaporation-induced decrease of $5 \%$.

\section{Results and Discussion}

Several experiments of thermocapillary convection coupling with evaporation effect have been carried out for different horizontal temperature differences $(\Delta T)$ in use of the above-mentioned experimental apparatus and measurements techniques. The interfacial temperature profiles, especially the vertical temperature discontinuities close to liquid-vapor interface were measured to analyze the nonequilibrium problem influenced by evaporation effect and thermocapillary convection.

To suppress the un-removable buoyancy effect, i.e. Rayleigh convection in ground experiments, the depth of the liquid layer should be set as thin as possible based on the definition of Bond number, which reflect the relative dominant of Rayleigh convection and thermocapillary convection. In present experiments, the depths of the liquid layers were always set to be smaller than $2.0 \mathrm{~mm}$.

Table 1 Thermo-physical properties of $0.65 \mathrm{cSt}$ silicone oil at $25^{\circ} \mathrm{C}$ and $1 \mathrm{~atm}$

\begin{tabular}{|c|c|c|c|c|c|c|c|c|c|}
\hline & $\rho \mathrm{Kg} \mathrm{m}^{-3}$ & $P_{S} \mathrm{~Pa}$ & $\sigma \mathrm{Nm}^{-1}$ & $L \mathrm{~J} \mathrm{Kg}^{-1}$ & $\mu \mathrm{Kg} \mathrm{m}^{-1} \mathrm{~s}^{-1}$ & $\lambda \mathrm{Wm}^{-1} \mathrm{~K}^{-1}$ & $\kappa \mathrm{m}^{2} \mathrm{~s}^{-1}$ & $\beta_{v} \mathrm{~K}^{-1}$ & $c_{p l} \mathrm{~J} \mathrm{Kg}^{-1} \mathrm{~K}^{-1}$ \\
\hline $0.65 \mathrm{cSt}$ & 761 & $4.70 \times 10^{3}$ & $1.59 \times 10^{-2}$ & $1.92 \times 10^{5}$ & $4.95 \times 10^{-4}$ & 0.1008 & $7.70 \times 10^{-8}$ & $1.34 \times 10^{-3}$ & $1.72 \times 10^{3}$ \\
\hline
\end{tabular}


Temperature Discontinuities in Different Horizontal Temperature Gradients

After the temperature difference $(\Delta T)$ between the two aluminum blocks and the horizontal temperature gradient in the liquid layer to be constant, temperature profiles at the vertical direction near the interface were measured by the $50 \mu \mathrm{m}$ thermocouple. Firstly, the measurements were performed at the center point of the test cell. Figure 2 shows the vertical temperature profiles across the vapor-liquid phase for a $2.0 \mathrm{~mm} 0.65 \mathrm{cSt}$ liquid layer with the temperature difference $(\Delta T)$ varying from $2{ }^{\circ} \mathrm{C}$ to $10^{\circ} \mathrm{C}$.

It could be seen from Fig. 2 that temperature discontinuities were also found across the vapor-liquid interface, as reported by Ward and Duan (2004). Whereas, it should be noted that our results were different from Ward's results in temperature gradients with vapor temperature higher than liquid temperature. It is mainly because of differences in experimental conditions. Ward's experiments were performed with a $4{ }^{\circ} \mathrm{C}$ water to suppress buoyancy effect, which means temperatures in vapor phase are always bigger than that in liquid. In present paper, the temperature differences $(\Delta T)$ were achieved with the temperature of cold aluminum sidewall close to atmosphere while the temperature of hot side higher than atmosphere. Therefore, temperatures in vapor phase are lower than that in liquid in most cases. Additionally, Ward performed experiments in a vacuum chamber with very low pressure to greatly enlarge evaporation effect. While present experiments were carried out in a free evaporating condition with the test cell open to air. It is indeed the relatively weak free evaporation resulting in smaller temperature discontinuities in present results compared with that found by Ward.

As shown in Fig. 2, there are different interfacial temperature profiles at the vertical direction with varying imposed temperature differences $(\Delta T)$, which is mainly induced by the co-influence of evaporation effect and thermocapillary convection. As we know, evaporation effect takes heat energy from the liquid-vapor interface to ambient air and reduces the interfacial temperature. While for thermocapillary convection, there will be an immediate convective flow from the hot side to the cold side at the interface, and a return flow at the bottom of liquid layer, as soon as the imposed horizontal temperature gradient in the liquid layer is established. This flow will bring heat energy from the hot side to increase the overall interfacial temperatures. When the temperature difference was small $\left(\Delta T=2^{\circ} \mathrm{C}\right)$, thermocapillary convection was relatively weak to slightly increase the interfacial temperature in the liquid layer with the temperature distributing in the liquid phase linearly as seen in Fig. 2a. While the evaporation effect was dominant in this case, more heat was absorbed from liquid than vapor due to the big thermal conductivity in liquid, which resulted in a temperature discontinuity with the interfacial temperature in vapor greater than that in the liquid by $0.28^{\circ} \mathrm{C}$. It is noted that same temperature discontinuity trends were both found in Popov's (2005) and Ward's (2001) experiments, which they inferred that condensation took place at the interface to release heat to the vapor phase after long-time stabilizing due to the relatively low liquid temperature. While in present experiments, the liquid temperatures were controlled to be always bigger than the vapor temperature, which means no condensation occurring at the vapor-liquid interface. When the temperature was low, it was inferred that the thermocapillary convection was not powerful enough to drive heat energy from the hot sidewall to sustain evaporation. Therefore, evaporation also absorbed heat from the vapor phase, which cooled the vapor temperature neighboring the liquid-vapor interface. Actually, recent numerical work by Saada et al. (2013) also found that the needed energy for evaporation was taken mainly from the gas phase when the efficiency of heat transferring was low.

With the temperature differences $(\Delta T)$ increasing to $4{ }^{\circ} \mathrm{C}$ and $6{ }^{\circ} \mathrm{C}$, thermocapillary convection would be strengthened to bring more heat energy from the hot side to the cold side, which increased the overall interfacial temperatures. In the meanwhile, more heat was needed to absorb from the vapor and liquid phase to sustain the enhancing evaporation effect, which accordingly decreased interfacial temperatures in the vapor and liquid phase. For the liquid phase, heat was transported by thermocapillary convection from hot side to supply the heat loss taken by evaporation, while no heat is supplied in vapor phase. As a result, a clear temperature discontinuity of $0.12{ }^{\circ} \mathrm{C}$ with the interfacial temperature in liquid greater than that in the vapor could be found. For the thermocapillary convection, the maximal flow carrying more heat is at the interface. Eventually, temperature rise by thermocapillary convection and temperature fall by evaporation at the interface achieved a balance, and an uniform-temperature layer with the thickness of about $0.5 \mathrm{~mm}$ was found, as indicated in Fig. 2b, c.

If the imposed temperature differences continued increasing $\left(\Delta T=8,10^{\circ} \mathrm{C}\right)$, bigger temperature discontinuities were found near the liquid-vapor interface, $0.25{ }^{\circ} \mathrm{C}$ and $0.34{ }^{\circ} \mathrm{C}$ as seen in Fig. $2 \mathrm{~d}$ and Fig. 2e, respectively. This mainly involved stronger thermocapillary convection induced by the increased temperature differences. Moreover, the enhancing thermocapillary convection flow extended into the whole liquid layer, and the bulk temperature below the interface were also enlarged. Additionally, a hydrothermal wave propagating obliquely from the cold to hot sidewall was found by the shadowgraph method with the temperature difference of $6{ }^{\circ} \mathrm{C}$, while developed into turbulence with the temperature difference of $10{ }^{\circ} \mathrm{C}$. It is very likely that the hydrothermal wave destroyed the thermal balance of evaporation and thermocapillary 
a

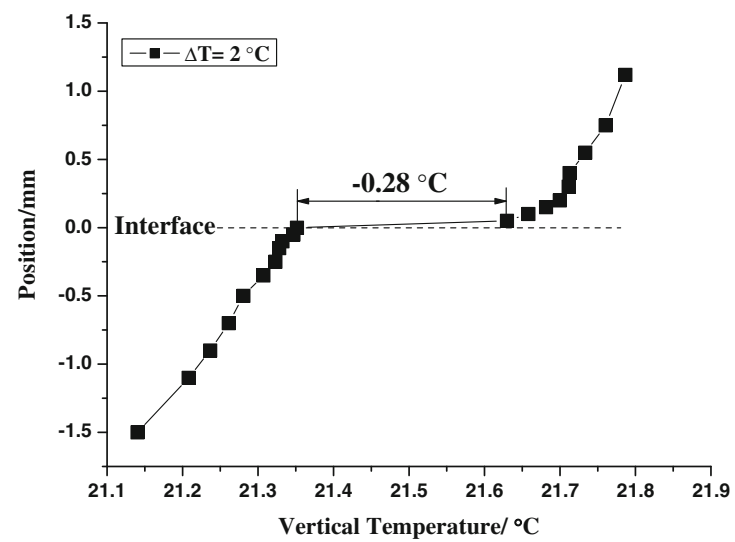

C

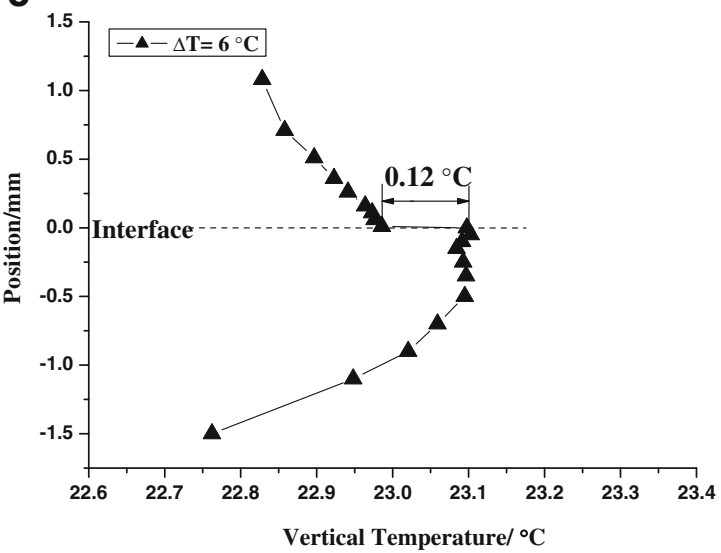

b

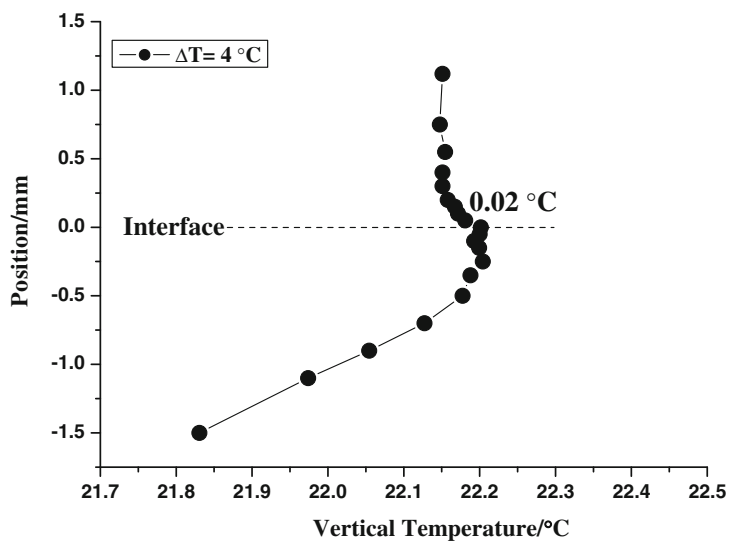

d

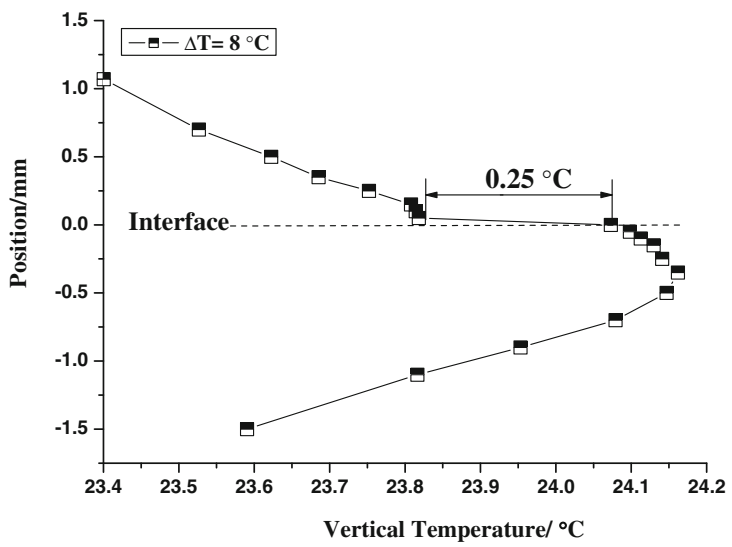

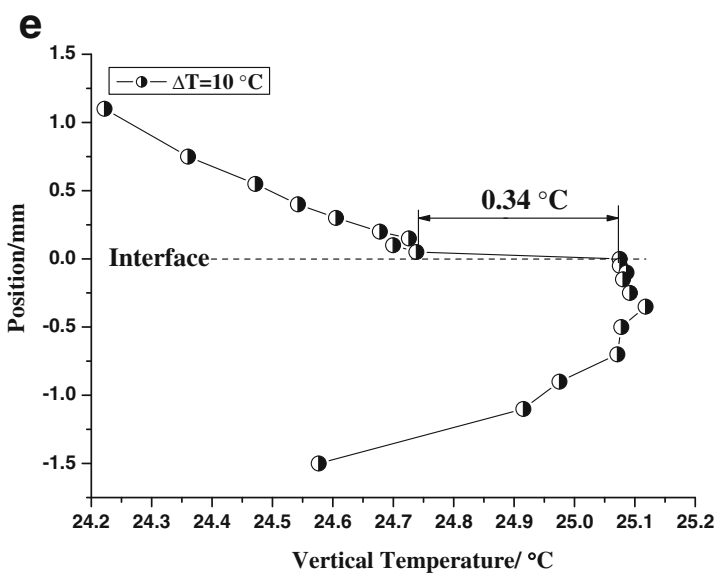

Fig. 2 The vertical temperature profiles across vapor-liquid phase in $0.65 \mathrm{cSt}$ silicone oil liquid layer at different horizontal temperature differences $(\Delta T)$ (Thickness of the liquid layer: $2.0 \mathrm{~mm}$. a $\Delta T=2{ }^{\circ} \mathrm{C} ; \mathbf{b} \Delta T=4{ }^{\circ} \mathrm{C} ; \mathbf{c} \Delta T=6{ }^{\circ} \mathrm{C} ; \mathbf{d} \Delta T=8{ }^{\circ} \mathrm{C} ; \mathbf{e ~} \Delta T=10^{\circ} \mathrm{C}$ )

convection, which decreased the interfacial temperature in the liquid phase. The coupling of overall temperature rise by thermocapillary convection and interfacial temperature fall by evaporation and hydrothermal wave in the liquid layer resulted in the maximal temperature about $0.5 \mathrm{~mm}$ below the interface.
Temperature Discontinuity Distribution Along the Center Line

The temperature discontinuity distribution was also measured along the center line paralleled to the horizontal temperature gradient at the positions with distances of 10 , 
$15,20,25,30 \mathrm{~mm}$ from the cold sidewall to establish its dependence on the position at the interface, as shown in Fig. 3.

In Fig. 3, similar tendency could be found at different positions: there was a temperature discontinuity with the interfacial temperature in vapor greater than that in the liquid probably induced by condensation at the interface when the temperature difference was small $\left(\Delta T=2{ }^{\circ} \mathrm{C}\right)$; A positive temperature discontinuity, i.e. interfacial temperature in vapor lower than that in the liquid, was achieved and it increased as the temperature difference increasing from $4{ }^{\circ} \mathrm{C}$ to $10{ }^{\circ} \mathrm{C}$. In addition, we found that the temperature discontinuity grew approximately linear from left to right of Fig. 3, i.e. from the cold side to the hot side of the liquid layer, of which we think owing to the interfacial temperature increasing from the cold wall to the hot wall (Fig. 4). More heat energy was brought by coupling of thermocapillary convection and thermal conduction in the liquid layer, while only thermal conduction worked for heat transfer in vapor phase. Consequently, temperature in liquid grew more than that in vapor with the increasing temperature difference. In other words, the temperature discontinuity was found to be strongly related to the interfacial temperature. And this result also partly supported Badam's conclusion (Badam et al. 2007) that the temperature discontinuity strongly depended on the heat transfer from vapor or liquid phase. Note that the maximal temperature discontinuity was not at the position of $30 \mathrm{~mm}$ when $\Delta T=10^{\circ} \mathrm{C}$. It is mainly because that co-influence of relatively strong thermal conduction and buoyancy convection increased the temperature in vapor at high temperature difference.

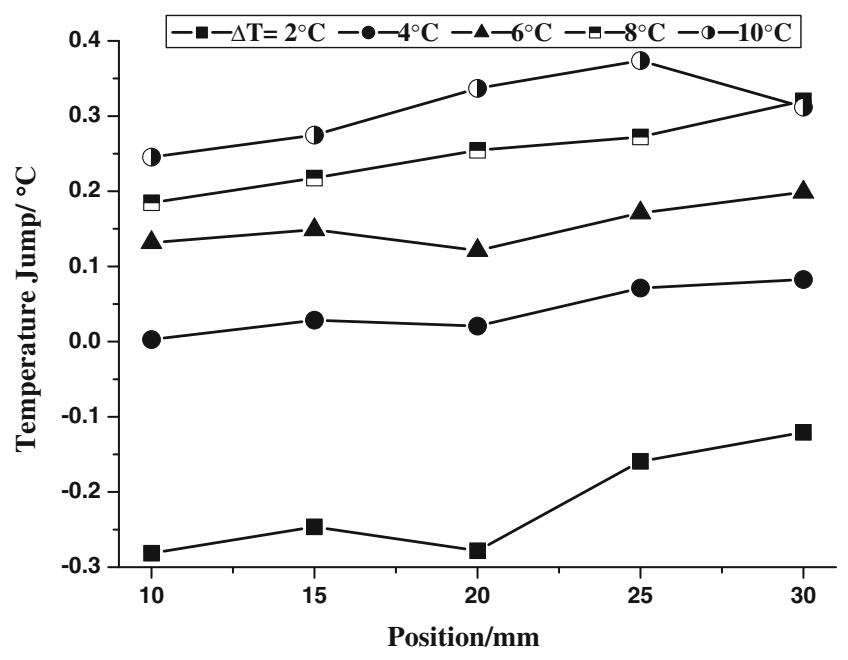

Fig. 3 The temperature discontinuities distribution (transverse) along the center line at different temperature differences (Liquid: $0.65 \mathrm{cSt}$ silicone oil; Thickness: $2.0 \mathrm{~mm}$ )

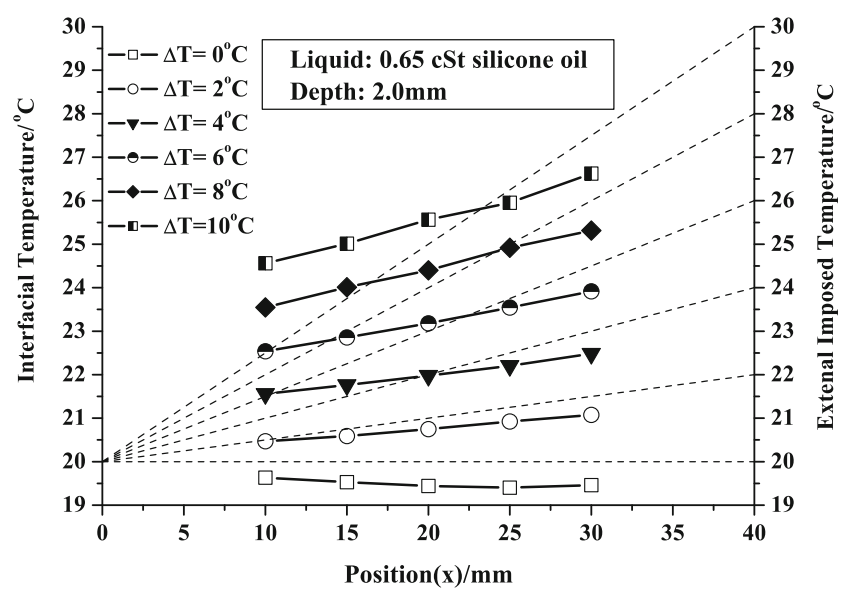

Fig. 4 The interfacial temperature profiles in $0.65 \mathrm{cSt}$ silicone oil at different temperature differences (Dash line: external imposed temperature gradients)

Temperature Discontinuity for Varying Depths of Liquid Layer

To verify the influence of the liquid layer depth on the temperature discontinuity, repeated experiments have been performed to measure the interfacial temperature profiles at the center point of the test cell across vapor-liquid phase under three different depths of the liquid layer, $1.0 \mathrm{~mm}$, $1.5 \mathrm{~mm}$ and $2.0 \mathrm{~mm}$, in $0.65 \mathrm{cSt}$ silicone oil. Note that these experiments were carried out in same conditions, i.e., same test cell, same ambient temperature and same horizontal temperature differences ranging from $2{ }^{\circ} \mathrm{C}$ to $10^{\circ} \mathrm{C}$. The comparison of the three temperature discontinuities versus temperature differences $(\Delta T)$ is presented in Fig. 5.

In Fig. 5, it could be seen that the three temperature discontinuity evolutions all exhibited rising linear tendency from negative to positive with $\Delta T$ increasing from $2{ }^{\circ} \mathrm{C}$ to

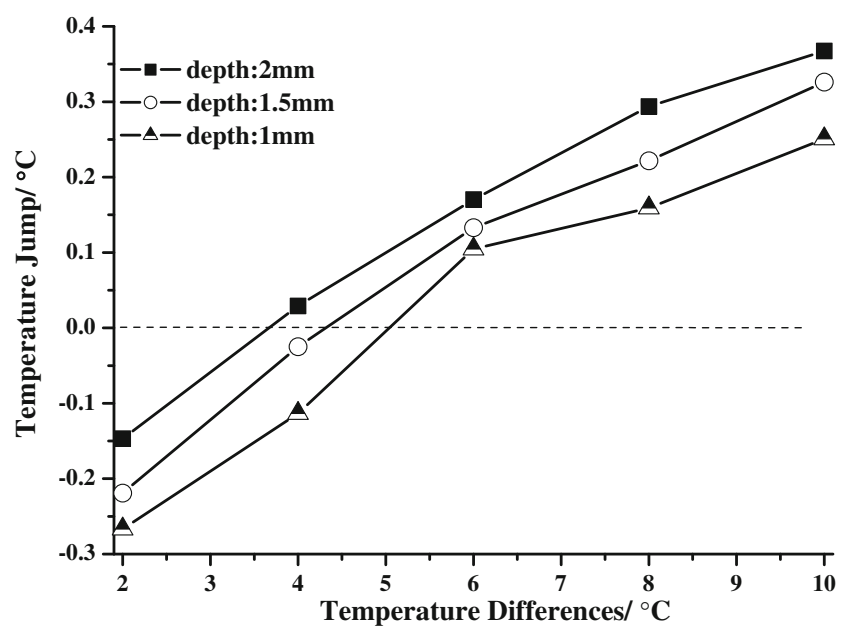

Fig. 5 Temperature discontinuities in $0.65 \mathrm{cSt}$ silicone oil under different temperature differences for varying depths of the liquid layer 
$10^{\circ} \mathrm{C}$. As we know, thermocapillary convection is directly influenced by the depth of liquid layer. Investigation of the flow fields showed that thermocapillary flow was usually enhanced in a deeper liquid layer. This means that more heat energy was transported from the hot side to the cold side in a deeper liquid layer. Although the evaporating was also strengthened, synchronous enhancing thermocapillary flow could bring more heat energy to compensate the heat loss taken by evaporation. Eventually, the interfacial temperature was always higher in deeper liquid layer at center point (Zhu and Liu 2010). As we mentioned above, the temperature discontinuity was strongly related to the temperature at the liquid-vapor interface. That's why we think that the temperature discontinuity grew with the increase of the liquid depth in Fig. 5.

\section{Conclusion}

Coupling influence of evaporation effect and thermocapillary convection on the vertical temperature profiles across the liquid-vapor interface was investigated experimentally. A temperature discontinuity has been found at the evaporation liquid-vapor interface. And the influences of imposed horizontal temperature differences, the streamwise spatial positions along the center line of the test cell, depths of the liquid layer were considered to analyze the physical mechanisms preliminarily.

With the temperature difference increasing, the temperature discontinuity had a transform from negative to positive owing to the enhancing thermocapillary convection in the liquid. And the temperature discontinuity also increased as the temperature difference increasing.

The temperature discontinuity at the free interface was found to be strongly related to the liquid surface temperature. Similar tendency with an approximate linear increase from the cold side to the hot side of the test cell were both found for the temperature discontinuity and the liquid surface temperature.

The temperature discontinuity grew with the increase of the liquid depth at the center point of the test cell, which was mainly resulted from the strengthened thermocapillary flow in deeper liquid layer.

Actually, there were always controversies on the temperature discontinuity and the depth of the liquid-vapor interface. Some people treated the interface as a non-thickness layer and the temperature discontinuity indeed existed across the interface. While another viewpoint doubted the existence of the temperature discontinuity, which was thought to be actual sharp temperature gradient across the interface with small thickness. In general, more work and further investigations are needed to fully understand the new found evaporating phenomenon.
Acknowledgments This research was financially supported by the National Natural Science Foundation of China (Grants No. 11072249 and No. 50890182) and the Strategic Pioneer Program on Space Science of Chinese Academy of Sciences (XDA04073000 and XDA04020202-2).

\section{References}

Badam, V.K., Kumar, V., Durst, F., Danov, K.: Experimental and theoretical investigations on interfacial temperature jumps during evaporation. Exp. Therm. Fluid Sci. 32(1), 276-292 (2007)

Duan, F., Ward, C.A.: Surface excess properties from energy transport measurements during water evaporation. Phys. Rev. E 72, 056302 (2005a)

Duan, F., Ward, C.A.: Surface-thermal capacity of D2O from mesurements made during steady-state evaporation. Phys. Rev. E 72, 056304 (2005b)

Duan, F., Badam, V.K., Durst, F., Ward, C.A.: Thermocapillary transport of energy during water evaporation. Phys. Rev. E 72, 056303 (2005)

Fang, G., Ward, C.A.: Temperature measured close to the interface of an evapoariting liquid. Phys. Rev. E 59(1), 417-428 (1999a)

Fang, G., Ward, C.A.: Examination of the statistical rate theory expression for liquid evaporation rates. Phys. Rev. E 59(1), 441-453 (1999b)

Hertz, H.: Über die Verdungstung der Flussigkeiten, inbesondere des Quecksilbers, im luftleeren Raume. Ann. Phys. Chem. 17, 177200 (1882)

Ji, Y., Liu, Q.S.: Coupling of evaporation and thermocapillary convection in a liquid layer with mass and heat exchanging interface. Chin. Phys. Lett. 25(2), 608-611 (2008)

Knudsen, M.: Die Maximale Verdampfungsgeschwindigkeit des Quecksilbers. Ann. Phys. Chem. 47, 697-708 (1915)

McGaughey, A.J.H., Ward, C.A.: Temperature discontinuity at the surface of an evaporating droplet. J. Appl. Phys. 91(10), 6406-6415 (2002)

Popov, S., Melling, A., Durst, F., Ward, C.A.: Apparatus for investigation of evaporation at free liquid-vapour interfaces. Int. J. Heat Mass Transfer 48, 2299-2309 (2005)

Saada, M.A., Chikh, S., Tadrist, L.: Evaporation of a sessile drop with pinned or receding contact line on a substrate with different thermophysical properties. Int. J. Heat Mass Transfer 58, 197-208 (2013)

Smith, M.K., Davis, S.H.: Instabilities of dynamic thermocapillary liquid layers. Part 1. convective instabilities. J. Fluid Mech. 132, 119 144 (1983a)

Smith, M.K., Davis, S.H.: Instabilities of dynamic thermocapillary liquid layers. Part 2. surface-wave instabilities. J. Fluid Mech. 132, $145-162(1983 b)$

Stefan, J.: Über die Theorie der Eisbildung, insbesondere über der Eisbildung in Polarmäre. Ann. Phys. Chem. 42, 269 (1891)

Ward, C.A., Fang, G.: Expression for predicting liquid evaporation flux: Statistical rate theory approach. Phys. Rev. E 59(1), 429-440 (1999)

Ward, C.A., Stanga, D.: Interfacial conditions during evaporation or condensation of water. Phys. Rev. E 64, 051509 (2001)

Ward, C.A., Duan, F.: Turbulent transition of thermocapillary flow induced by water evaporation. Phys. Rev. E 69(5), 056308 (2004)

Yamamura, M., Nagai, K., Kajiwara, T., Adachi, K.: Stripe pattern breakup in evaporating liquid layer on a plane with horizontal temperature gradient. Chem. Eng. Process. 42, 395-402 (2003)

Zhu, Z.Q., Liu, Q.S.: Coupling of thermocapillary convection and evaporation effect in a liquid layer when the evaporating interface is open to air. Chin. Sci. Bull. 55(3), 233-238 (2010) 